\title{
Pseudo-Gruneisen Parameter and Internal Pressure of Binary Mixtures from Different Approaches
}

\author{
R. K. Shukla*1, V. S. Gangwar ${ }^{1}$, Sadhna Shukla ${ }^{2}$, Manish Tiwari ${ }^{2}$ and Kirti Tenguriya ${ }^{3}$ \\ ${ }^{1}$ Department of Chemistry, V.S.S.D.College, Kanpur-208002- India. \\ ${ }^{2}$ Department of Chemistry,M G C G university,Chitrakoot,Satna,M.P.- India \\ ${ }^{3}$ Department of Chemistry, Govt. Science college, Gwalior,M.P.- India \\ E-mail- rajeevshukla47@ rediffmail.com
}

Received 03 August 2014, Revised 13 February 2015, Accepted 27 February 2015

\begin{abstract}
Density and speed of sound were measured earlier by us for binary liquid mixtures formed by Benzonitrile, Chlorobenzene, Benzyl chloride and Benzyl alcohol with Benzene at temperature range 298.15 to $313.15 \mathrm{~K}$ and atmospheric pressure over the whole concentration range. Pseudo-Gruneisen parameter and internal pressure were derived from the measured values of density and ultrasonic velocity. These values were compared with the theoretical values obtained by the utilization of Flory theory, Ramaswamy and Anbananthan model and model suggested by Glinski to predict the behavior of weakly interacting liquids. The observed properties derived from measured data were fitted to Redlich-Kister polynomial relation to estimate the binary coefficients and standard errors. Excess Pseudo-Gruneisen parameter for these binary mixtures was computed to study the molecular interactions involved in the liquid systems.
\end{abstract}

Keywords: Pseudo-Gruneisen parameter; internal pressure; Flory theory; Ramaswamy and Anbananthan model: Redlich-Kister.

\section{Introduction}

Gruneisen parameter is an important tool to study the thermodynamic and other properties of solid crystalline lattice [1].The concept of anharmonicity of the lattice is characterized by the Gruneisen parameter. It is well established that liquids support a quasi-crystalline model for their structure, the lattice nature being increased at high pressure and low temperature and the Gruneisen parameter can be used to study them. Its pseudo counterpart has been found to be suitable to investigate the internal structures, clustering phenomenon and other quasi crystalline properties of liquids, liquid mixtures [2-5], liquefied gases [6], liquid metal alloys [7] and higher alkanes [2].

The role of internal pressure in liquid solution thermodynamics was recognized by Hildebrand [8]. The use of this property for a long time was qualitative but recently its usefulness has been explored for quantitative study of intermolecular forces. Pioneer attempts have been made by several workers [9-15] to study the significance and its correlation with other properties. The internal pressure can be computed by indirect methods as suggested by Suryanarayan. In recent past, substantial amount of work has been carried out by many workers to study the excess thermodynamic functions like excess internal pressure; excess energy of vaporization, excess pseudo-Gruneisen parameter is still in progress [16-20].

In the present investigation, Pseudo-Gruneisen parameter, excess pseudo-Gruneisen parameter and internal pressure were derived from the measured values of density and ultrasonic velocity [21] for binary liquid mixtures formed by Benzonitrile, Chlorobenzene, Benzyl chloride and Benzyl alcohol with Benzene at temperature range 298.15 to
313.15 $\mathrm{K}$ and atmospheric pressure over the whole concentration range. A comparison of experimental and theoretical speed of sound is provided in Table 1. These derived values of pseudo-Gruneisen parameters were compared with the theoretical values obtained by the utilization of Flory theory [22-23], Ramaswamy and Anbananthan model [24] and model suggested by Glinski [25] to predict the behavior of weakly interacting liquids. The observed properties derived from measured data were fitted to Redlich-Kister polynomial relation [26] to estimate the binary coefficients and standard errors.

\section{Theoretical \\ 2.1 Flory Theory}

Assuming two body interactions, Flory evaluated the reduced and characteristic parameters of the liquid mixture from the reduced equation of state derived from the resulting partition function as;

$$
\frac{\tilde{P} \widetilde{V}}{\tilde{T}}=\frac{\widetilde{V}^{1 / 3}}{\widetilde{V}^{1 / 3}-1}-\frac{1}{\widetilde{V} \widetilde{T}}
$$

where, $\tilde{P}=\frac{P}{P^{*}}, \tilde{T}=\frac{T}{T^{*}}$, and $\tilde{V}=\frac{V}{V^{*}}$ that are reduced parameters and $P^{*}, T^{*}, V^{*}$ are characteristic parameters. The coefficient of thermal expansion, $\alpha$, is evaluated from the reduced equation of state as:

$$
a_{\text {Flory }}=\frac{1}{T\left[\frac{1}{3\left(\widetilde{V}^{\frac{1}{3}}-1\right)-1}\right]}
$$


adiabatic and compressibility is given by,

$\beta_{s}=\frac{1}{u^{2} \rho}$

where $u$ and $\rho$ are experimental speed of sound and density of binary liquid mixture. By combining above equations Pseudo-Greneisen parameter for liquid mixtures is obtained as;

$\tau_{\text {Flory }}=\frac{1}{T}\left[\frac{1}{\beta_{S}}-\gamma_{P}-\frac{1}{a}\right]$

where $\gamma_{\mathrm{P}}$ is the thermal pressure coefficient related to the following expression as;

$\gamma_{P}=\frac{P^{*}}{T \widetilde{V}^{2}}$

$\gamma_{\mathrm{P}}$ is also related to internal pressure of the liquid mixture as;

$P_{i_{\text {Flory }}}=T \cdot \gamma_{P}$

For observed value of Pesudo-Gruneisen parameter, $\gamma_{P}$ is evaluated by the relation as;

$\gamma_{P}=\frac{a}{\beta_{T}}$

Thermal expansion coefficient, $\alpha$ and adiabatic compressibility, $\beta_{\mathrm{T}}$ are defined as;

$$
\begin{aligned}
a & =\left(0.0191 \times \beta_{T}\right)^{1 / 4} \\
\beta_{T} & =1.71 \times 10^{-3} / T^{4 / 9} \times u^{2} \times \rho^{4 / 3}
\end{aligned}
$$

\subsection{Ramswamy and Anbananthan Model}

Ramswamy and Anbananthan [24] proposed the model based on the assumption of linearity of acoustic impedance with the mole fraction of components. Further it is assumed, that an equilibrium physical property such as viscosity, refractive index, surface tension etc which are based on linearity can also be predicted. Glinski [25] assumed that when solute is added to solvent the molecules interact according to

$A+B \leftrightarrow A B$

and the association constant, $\mathrm{K}_{\mathrm{as}}$, can be defined as;

$K_{a s}=\frac{[A B]}{[A][B]}$

where $[A]$ is amount of solvent and $[B]$ is amount of solute in the liquid mixture.

By applying the condition of linearity with composition, peudo-Gruneisen parameter can be obtained as;

$\Gamma_{\text {cal }}=\mathrm{x}_{\mathrm{A}} \Gamma_{\mathrm{A}}+\mathrm{x}_{\mathrm{AB}} \Gamma_{\mathrm{AB}}$

where $x_{A}, x_{A B}, \Gamma_{A}, \Gamma_{A B}$ and $\Gamma_{c a l}$ are the mole fraction of A, mole fraction of associate $\mathrm{AB}$, peudo-Gruneisen parameter of $\mathrm{A}$
peudo-Gruneisen parameter of associate $\mathrm{AB}$ and calculated peudo-Gruneisen parameter respectively. The associate $A B$ cannot be obtained in its pure form. Following simplifications have been made in Eq. (12), firstly, molar concentration term should be replaced by activities for concentrated solution and second, the equilibrium reaction is not complete by definition; i.e. there are also molecules of non-associated component present in the liquid mixture even prevailing in the high solute content. The Eq. (12) takes the form,

$\Gamma_{\text {cal }}=\left[\mathrm{x}_{\mathrm{A}} \Gamma_{\mathrm{A}}+\mathrm{x}_{\mathrm{B}} \Gamma_{\mathrm{B}}+\mathrm{x}_{\mathrm{AB}} \Gamma_{\mathrm{AB}}\right]$

The general idea of this model can be, however, exploited as;

$K_{a s}=\frac{[A B]}{\left(C_{A}-[A B]\right)\left(C_{B}-[A B]\right)}$

where $C_{A}$ and $C_{B}$ are initial molar concentrations of the components. One can take any value of association constant, $\mathrm{K}_{\mathrm{as}}$, and calculate the equilibrium value of $[\mathrm{AB}]$ for every composition of the mixture. Replacing molar concentration by equimolar activities for concentrated solution, Eq. (14) becomes,

$$
K_{a s}=\frac{a_{A B}}{\left(a_{A}-a_{A B}\right)\left(a_{B}-a_{A B}\right)}
$$

where $a_{A}, a_{B}$ and $a_{A B}$ are the activity of component A, Component $\mathrm{B}$ and associate, $\mathrm{AB}$ respectively.

Similarly, assuming any value of peudo-Gruneisen parameter for hypothetical pure component $\mathrm{AB}$, the peudoGruneisen parameter of liquid mixture, $\Gamma_{\text {cal }}$ can be calculated by substituting the value of association constant. Now, it is possible to compare the peudo-Gruneisen parameter calculated using Eq (14) with the experimental values. On changing both the adjustable parameters $\mathrm{K}_{\mathrm{as}}$ and $\Gamma_{\mathrm{AB}}$ gradually, one can get different values of the sum of squares of deviations,

$S=\Sigma\left(\Gamma_{o b s}-\Gamma_{c a l}\right)^{2}$

where $\Gamma_{\text {obs }}$ and $\Gamma_{\text {cal }}$ are the observed and calculated peudoGruneisen parameter respectively.

The minimum value of $S$ can be obtained theoretically by a pair of the fitted parameters. But we found that for some $K_{a s}$ and $\Gamma_{A B}$, the value of $S i \mathrm{~s}$ high and changes rapidly, and for others, it is low and changes slowly when changing the fitted parameters. The condition which is prevailing in the process of adjustment is that the value of $\Gamma_{A B}$ should not be much lower than the lowest $\Gamma_{o b s}$ of thesystem or much higher than the highest one. Quantitatively, it should be reasonable to accept the pair of adjustable parameters $K_{a s}$ and $\Gamma_{A B}$ which has the physical sense and which reproduces the experimental physical property satisfactorily.

On inspecting the results obtained from Ramaswamy and Anbananthan model, Glisnki [25] suggested the equation assuming additivity with the volume fraction, $\phi$ of the components, the refined version of Natta and Baccaredda model [27] as,

$\tau_{c a l}=\frac{\tau_{A} \tau_{B} \tau_{A B}}{\phi_{A} \tau_{B} \tau_{A B}+\phi_{B} \tau_{A} \tau_{A B}+\phi_{A B} \tau_{A} \tau_{B}}$

where $\Gamma_{\text {cal }}$ is the theoretical peudo-Gruneisen parameter of binary liquid mixture, $\phi_{\mathrm{A}}, \phi_{\mathrm{B}}$ are the volume fractions of component $\mathrm{A}$ and $\mathrm{B}$ and $\Gamma_{A}, \Gamma_{B}$ and $\Gamma_{A B}$ are the peudo- 
Gruneisen parameter of components A, B and AB. The numerical procedure and determination of association constant, $K_{a s}$, were similar to that described before and the advantage of this method as compared with the earlier one was that the data on densities of liquid mixture are not necessary except those of pure components needed to calculate the volume fractions.

Table 1. Comparison of Density with literature data for pure components at 293.15, 298.15, 303.15, 308.15 and 313.15 K.

\begin{tabular}{|c|c|c|c|c|c|c|}
\hline $\begin{array}{l}\text { Comp } \\
\cdot \\
\end{array}$ & $\alpha .10^{3} \mathrm{~K}$ & $\begin{array}{l}\beta_{\mathrm{T} .10^{12}} \\
\mathbf{P a}\end{array}$ & $\begin{array}{l}\mathrm{V} / \mathrm{cm}^{3} \\
\mathrm{~mole}^{-1}\end{array}$ & $\mathbf{T} /{ }^{\circ} \mathbf{K}$ & $\begin{array}{l}\rho_{\text {exp }} / \\
\text { g.cm }^{-3}\end{array}$ & $\begin{array}{l}\text { Plit/ } \\
\text { g.cm-3 }\end{array}$ \\
\hline \multirow[t]{4}{*}{ B } & 1.218023 & 94.6097 & 89.319 & 298.15 & 0.8732 & $\begin{array}{l}0.8736 \\
{[32]}\end{array}$ \\
\hline & 1.21875 & 94.7791 & 89.936 & 303.15 & 0.8680 & $\begin{array}{l}0.8683 \\
{[30]}\end{array}$ \\
\hline & 1.228696 & 97.1185 & 90.730 & 308.15 & 0.8653 & - \\
\hline & 1.24239 & 100.402 & 91.132 & 313.15 & 0.8575 & $\begin{array}{l}0.8576 \\
{[30]}\end{array}$ \\
\hline \multirow[t]{4}{*}{ BN } & 0.997994 & 52.0415 & 103.078 & 298.15 & 1.0003 & $\begin{array}{l}1.0006 \\
{[30]}\end{array}$ \\
\hline & 1.008302 & 53.6709 & 103.565 & 303.15 & 0.9976 & $\begin{array}{l}0.9978 \\
{[30]}\end{array}$ \\
\hline & 1.010971 & 54.0982 & 104.841 & 308.15 & 0.9941 & - \\
\hline & 1.016819 & 55.0424 & 105.245 & 313.15 & 0.9919 & - \\
\hline \multirow[t]{4}{*}{ CB } & 0.99078 & 50.9211 & 102.234 & 298.15 & 1.1004 & $\begin{array}{l}1.1009 \\
{[30]}\end{array}$ \\
\hline & 0.997456 & 51.9574 & 102.747 & 303.15 & 1.0951 & $\begin{array}{l}1.0955 \\
{[30]}\end{array}$ \\
\hline & 1.004295 & 53.0335 & 102.841 & 308.15 & 1.0922 & $\begin{array}{l}1.0926 \\
{[33]}\end{array}$ \\
\hline & 1.026654 & 56.6551 & 104.013 & 313.15 & 1.0863 & $\begin{array}{l}1.0878 \\
{[33]}\end{array}$ \\
\hline \multirow[t]{4}{*}{ BC } & 1.059322 & 62.2374 & 115.649 & 298.15 & 1.0899 & - \\
\hline & 1.067131 & 63.6240 & 116.158 & 303.15 & 1.0890 & $\begin{array}{l}1.0897 \\
{[31]}\end{array}$ \\
\hline & 1.070387 & 64.2080 & 116.662 & 308.15 & 1.0894 & - \\
\hline & 1.074842 & 65.0132 & 116.892 & 313.15 & 1.0802 & $\begin{array}{l}1.0806 \\
{[30]}\end{array}$ \\
\hline \multirow[t]{4}{*}{$\mathbf{B A}$} & 1.015504 & 54.8292 & 103.821 & 298.15 & 1.0412 & $\begin{array}{l}1.0413 \\
{[30]}\end{array}$ \\
\hline & 1.021907 & 55.8729 & 104.241 & 303.15 & 1.0370 & $\begin{array}{l}1.0376 \\
{[30]}\end{array}$ \\
\hline & 1.033784 & 57.8437 & 105.450 & 308.15 & 1.0372 & - \\
\hline & 1.063372 & 62.9539 & 107.978 & 313.15 & 1.0366 & - \\
\hline
\end{tabular}

B: Benzene, BN: Benzonitrile, CB: Chlorobenzene,

BC: Benzylchloride, BA: Benzyl alcohol

\section{Result and Discussion}

Relations between associations phenomenon in liquids were analyzed earlier [28] by considering van der Waals equation of state which was based only on simple averaged geometrical deviations without analyzing the system in terms of equilibrium. The association phenomenon has been related usually the deviation of different quantities from additivity. Ramaswami and Anbananthan derived the model based on the assumption of linearity of acoustic impedance with the mole fraction of components which was corrected [25] and tested [28] to predict the associational behavior. The quantities analyzed were refractive index, molar volume, viscosity, intermolecular free length. Prediction of ultrasonic velocity from this approach is our first attempt. The results of fittings obtained from the model were utilized properly. The basic doubt regarding this model except the assumption of linearity of ultrasonic velocity with mole fraction is that these liquids have poor affinity to form dimmers. The calculations were performed using a computer program which allows fittings easily both the adjustable parameters simultaneously or the parameters were changed manually.

We constructed the data sheet in a computer program with association constant $\mathrm{K}_{\mathrm{as}}$ and $\Gamma_{\mathrm{A}, \mathrm{B}}$ as the fitted parameters. On changing these parameters, the equilibrium concentrations of species $[\mathrm{A}],[\mathrm{B}]$ and $[\mathrm{AB}]$ will change and the pseudo-Gruneisen parameter can be computed. The difference between experimental and theoretical values for pseudo-Gruneisen parameter is used to obtain the sum of squares of deviation. It is assumed that in solution three associates instead of two are formed (A, B and AB). The values of pseudo-Gruneisen parameter in pure associate can be treated as a fitted one with the value of $K_{a s}$.

The standard deviation $\Delta \Gamma$ can be represented mathematically by Redlich-Kister polynomial equation [26] for correlating the experimental data as;

$$
y=x_{i}\left(1-x_{1}\right) \sum_{i=0}^{p} A_{i}\left(2 x_{1}-1\right)^{i}
$$

where $y$ refers to deviation in pseudo-Gruneisen parameter $, y,(\Delta I), \mathrm{x}_{1}$ is the mole fraction and $\mathrm{A}_{\mathrm{i}}$ is the coefficient. The values of coefficients were determined by a multiple regression analysis based on the least square method and are summarized along with the standard deviations between the experimental and fitted values of the respective function in Table 2. The values of standard deviations lie between $4.7 \times 10^{-2}-2.88 \times 10^{-3}$ respectively.

Table 2. Coefficients of the Redlich-Kister Equation and Standard Deviations ( $\delta$ ) for Binary Liquid Mixtures at Various Temperatures.

\begin{tabular}{|c|c|c|c|c|c|c|}
\hline \multicolumn{7}{|c|}{ Benzene+benzonitrile } \\
\hline & $\mathbf{T}$ & $\mathbf{A}_{0}$ & $\mathbf{A}_{1}$ & $\mathbf{A}_{2}$ & $\mathbf{A}_{3}$ & $\begin{array}{c}(\delta) \text { Std } \\
\text { dev }\end{array}$ \\
\hline \multirow[t]{4}{*}{$\Delta \Gamma$} & 298.15 & -0.4853 & 0.1947 & -0.0670 & -0.1777 & 0.0087 \\
\hline & 303.15 & -0.5431 & $\begin{array}{c}0.1510 \\
-\end{array}$ & -0.0301 & 0.0189 & 0.0101 \\
\hline & 308.15 & -0.4878 & 0.1228 & 0.1048 & -0.3550 & 0.0146 \\
\hline & 313.15 & -0.4878 & 0.4257 & 0.2020 & 0.8098 & 0.0175 \\
\hline \multicolumn{7}{|c|}{ Benzene +chlorobenzene } \\
\hline \multirow[t]{4}{*}{$\Delta \Gamma$} & 298.15 & -0.1620 & $\begin{array}{c}- \\
0.6209\end{array}$ & -0.0742 & -0.1910 & 0.0093 \\
\hline & 303.15 & -0.1578 & $\begin{array}{c}0.6764 \\
-\end{array}$ & 0.0947 & -0.0851 & 0.0108 \\
\hline & 308.15 & -0.1477 & 0.6336 & 0.0536 & -0.2525 & 0.0084 \\
\hline & 313.15 & -0.0582 & 0.5425 & 0.3648 & 0.4125 & 0.0093 \\
\hline \multicolumn{7}{|c|}{ Benzene + benzalchloride } \\
\hline \multirow[t]{4}{*}{$\Delta \Gamma$} & 298.15 & -0.0712 & $\begin{array}{c}- \\
0.4388 \\
-\end{array}$ & 0.5654 & 0.5991 & 0.0106 \\
\hline & 303.15 & -0.0499 & 0.4774 & 0.3859 & 0.9171 & 0.0093 \\
\hline & 308.15 & -0.0930 & 0.3418 & 1.4715 & -0.6704 & 0.0166 \\
\hline & 313.15 & -0.6033 & 0.0513 & 0.5973 & 0.2723 & 0.0181 \\
\hline \multicolumn{7}{|c|}{ Benzene +benzylalcohol } \\
\hline \multirow[t]{4}{*}{$\Delta \Gamma$} & 298.15 & -0.2795 & 0.0590 & 0.2292 & -0.0715 & 0.0047 \\
\hline & 303.15 & -0.1239 & $\begin{array}{c}0.0654 \\
-\end{array}$ & 0.0832 & -0.2021 & 0.0102 \\
\hline & 308.15 & -0.2467 & $\begin{array}{c}0.2752 \\
-\end{array}$ & 0.3804 & 0.8708 & 0.0171 \\
\hline & 313.15 & -0.4120 & 0.2075 & 0.3521 & 0.0070 & 0.0288 \\
\hline
\end{tabular}

The absolute average percent deviations (AAPD) in pseudo-Gruneisen parameter obtained from different models are provided in Table 3. A care full perusal of Tables 3 and 4 indicate that associated processes provide fairly good 
results as compared to non-associated. Higher deviation values in PFP model can be explained as the model was developed for non-electrolyte $\gamma$-meric spherical chain molecules and the system under investigation have interacting and associating properties. Moreover, the expression used for the computation of thermal expansion coefficient, $\alpha$ and adiabatic compressibility, $\beta_{T}$ [29] are also empirical in nature.

Table 3. Comparison of Absolute Average Percent Deviation $(A A P D)$ values obtained from various liquid state models at Kas $=0.001$.

\begin{tabular}{|c|c|c|c|c|c|c|}
\hline \multicolumn{7}{|c|}{ Benzene+benzonitrile } \\
\hline Temp. & $\Gamma_{\text {PFP }}$ & $\Gamma_{\mathrm{RS}}$ & $\Gamma_{\mathrm{GLI}}$ & $\begin{array}{l}\text { PipFP.10 } \\
/ \mathrm{Pa}\end{array}$ & $\begin{array}{l}\text { PiRs.10 }^{-9} \\
/ \mathrm{Pa}\end{array}$ & $\begin{array}{l}\text { Pigli.10 }^{-9} \\
/ \mathrm{Pa}\end{array}$ \\
\hline 298.15 & 5.6253 & 2.3612 & 3.1674 & 6.0895 & 6.8990 & 9.1750 \\
\hline 303.15 & 5.9932 & 2.4811 & 3.2363 & 6.0679 & 7.2426 & 9.3679 \\
\hline 308.15 & 6.0657 & 2.4992 & 3.2886 & 5.5162 & 7.2920 & 9.5136 \\
\hline 313.15 & 6.5190 & 2.2901 & 3.1461 & 5.5815 & 6.6788 & 9.0849 \\
\hline \multicolumn{7}{|c|}{ Benzene+chlorobenzene } \\
\hline 298.15 & 4.5532 & $\begin{array}{c}2.211 \\
6 \\
2.063\end{array}$ & 1.8829 & 3.4635 & 6.4735 & 5.5282 \\
\hline 303.15 & 4.6353 & $\begin{array}{c}5 \\
2.340\end{array}$ & 1.7560 & 3.4258 & 6.0485 & 5.1622 \\
\hline 308.15 & 5.1246 & $\begin{array}{c}3 \\
1.046\end{array}$ & 2.0551 & 3.7008 & 6.8400 & 6.0227 \\
\hline 313.15 & 4.2779 & 0 & 0.8236 & 3.6936 & 3.0973 & 2.4477 \\
\hline \multicolumn{7}{|c|}{ Benzene+benzalchloride } \\
\hline 298.15 & 3.2169 & 0.4036 & 0.3612 & 5.0055 & 1.2118 & 1.0883 \\
\hline 303.15 & 3.4629 & 0.4447 & 0.4470 & 5.3942 & 1.3355 & 1.3083 \\
\hline 308.15 & 3.9764 & 0.6653 & 0.6758 & 7.0755 & 2.0026 & 1.7852 \\
\hline 313.15 & 5.3303 & 0.6265 & 0.6331 & 25.8374 & 1.8724 & 1.5333 \\
\hline \multicolumn{7}{|c|}{ Benzene+benzylalcohol } \\
\hline 298.15 & 4.2271 & 1.4890 & 0.4345 & 2.2318 & 4.3944 & 2.6666 \\
\hline 303.15 & 4.1700 & 1.1617 & 0.5912 & 2.1800 & 3.4396 & 1.7878 \\
\hline 308.15 & 4.3388 & 1.2700 & 0.5113 & 3.2411 & 3.7610 & 2.2523 \\
\hline 313.15 & 6.7962 & 2.8875 & 0.8976 & 3.7908 & 8.3644 & 6.9699 \\
\hline
\end{tabular}

Mixture data are presented in Table 4. Density and speed of sound of mixture data were taken from reference [21]. With the increase of mole fraction, the values of observed pseudo-Gruneisen parameter, observed internal pressure, theoretical pseudo-Gruneisen parameters and theoretical internal pressure obtained from all the models decrease at all temperatures whereas no regular trends are observed for excess pseudo-Gruneisen parameters. For excess properties, sign and magnitude are of much important to describe the molecular interactions involved in the liquid system. Negative values of excess observed pseudo-Gruneisen parameters, $\Gamma^{E}$ obs for all the systems show the strong molecular interactions between the liquid components. Dispersion type interactions and structural effects arising from interstitial accommodation because of differences in molecular volumes and free volumes between liquid components contribute negative terms to $\Gamma^{E}$. The repulsive forces between the loan pair of electrons leads to positive values of $\Gamma^{E}$ suggest the presence of weak interactions between the component molecules and the favoring packing of unlike molecules.

\section{Conclusions}

Conclusively, models assuming associated processes give more reliable results as compared to non-associated processes and helpful in deducing the internal structure of associates through the fitted values of pseudo-Gruneisen parameter and internal pressure in a hypothetical pure associate and observed dependence of concentration on composition of a mixture.

\section{Acknowledgment:}

Authors are very thankful to U.G.C., New Delhi for financial and Department of Chemistry, V.S.S.D. College, for cooperation.

\section{Nomenclature \\ $\alpha \quad$ Thermal Expansion Coefficient / K \\ $\beta_{T} \quad$ Isothermal Compressibility / $\mathrm{Pa}$ \\ $\gamma_{p} \quad$ Thermal Pressure Coefficient K.Pa ${ }^{-1}$ \\ $x \quad$ Mole fraction / gm. \\ $\Gamma \quad$ Pseudo Gruneisen parameter \\ $T \quad$ Absolute Temperature $/{ }^{\circ} \mathrm{K}$ \\ $V \quad$ Molar Volume $/ \mathrm{cm}^{3} \mathrm{~mole}^{-1}$ \\ $A_{0} \quad$ Ist order Coefficients of the R-K Equation \\ $A_{1} \quad 2^{\text {nd }}$ order Coefficients of the R-K Equation \\ $A_{2} \quad 3^{\text {rd }}$ order Coefficients of the R-K Equation \\ $A_{3} \quad 4^{\text {th }}$ order Coefficients of the R-K Equation \\ $\phi \quad$ Volume Fraction $/ \mathrm{cm}^{3} \mathrm{~mole}^{-1}$ \\ $M \quad$ Molecular Weight/g. \\ $\rho \quad$ Density/g.cm ${ }^{-3}$ \\ $P^{*} \quad$ Characteristic Pressure/Pa \\ $T^{*} \quad$ Characteristic Temperature $/{ }^{\circ} \mathrm{K}$ \\ $V^{*} \quad$ Characteristic, Core Volume $/ \mathrm{cm}^{3} \mathrm{~mole}^{-1}$ \\ $P \quad$ Reduced Pressure / $\mathrm{Pa}$ \\ $V \quad$ Reduced Volume $/ \mathrm{cm}^{3} \mathrm{~mole}^{-1}$ \\ $\tilde{T} \quad$ Reduced Temperature $/{ }^{\circ} \mathrm{K}$ \\ $\beta_{s} \quad$ Isoentropic Compressibility / $\mathrm{Pa}$ \\ $K_{\text {as }} \quad$ Association constant \\ $X_{A B} \quad$ Mole fraction of associate / g. \\ $\mathrm{C}_{\mathrm{A}} \& \mathrm{C}_{\mathrm{B}} \quad$ Initial molar concentrations of $\mathrm{A} \& \mathrm{~B}$ \\ $S \quad$ Sum of squares of deviations \\ $a_{A}, \quad$ Activity of component A / g.mole. lit $^{-1}$ \\ $a_{B} \quad$ Activity of component B / g.mole. lit $^{-1}$ \\ $a_{A B} \quad$ Activity of associate AB / g.mole. lit $^{-1}$ \\ $\delta \quad$ Standard deviation \\ $\mathrm{Pi} \quad$ Internal pressure / $\mathrm{Pa}$ \\ $\Delta \Gamma \quad$ Deviation in pseudo-Gruneisen parameter \\ $u \quad$ Speed of sound $/ \mathrm{ms}^{-1}$ \\ $\Gamma^{E} \quad$ Excess pseudo-Gruneisen parameter}

$\begin{array}{ll}\text { Subscript } & \\ \text { PFP } & \text { Prigogine-Flory-Patterson } \\ \text { RS } & \text { Ramaswami \&Anbananthan } \\ \text { GLI } & \text { Glinski } \\ \text { obs } & \text { Observed } \\ \text { cal } & \text { Calculated } \\ \text { lit } & \text { Literature } \\ \text { exp } & \text { Experimental }\end{array}$

\section{References:}

[1] L. Knopoff, J. N. Shapiro, "Pseudo-Grüneisen Parameter for Liquids", Phys. Rev. B, 1, 2893, 1970.

[2] R. K. Shukla, S. K. Shukla, V. K. Pandey, P. Awasthi, "Excess Internal Pressure, Excess Energy of Vaporization and Excess Pseudo-Gruneisen Parameter of Binary, Ternary and Quaternary Liquid Mixtures", $J$. Molliq. Liq., 137, 104-109, 2008.

[3] R. K. Shukla, Atul Kumar, Kirti Srivastava, Sanjay Gupta, Shilpi Yadav, "A Comparative Study of PFP and 
BAB Models in Predicting the Excess ThermoAcoustical and its Allied Properties of Liquid Ternary Mixtures", J. Molliq. Liq., 140, 25-32, 2008.

[4] J. D. Pandey, R. Day, "Excess Internal Pressure and Excess Pseudo-Gruneisen Parameter of Binary Liquid Mixtures", Acous. Lett., 24, 105-109, 2000.

[5] J. D. Pandey, G. P. Dubey, R. Day, S. N. Dubey, "Temperature and Pressure Dependence of ThermoAcoustical Parameters of Liquid Argon and Krypton", Acta Acustica, 83, 90-92, 1997.

[6] J. D. Pandey, A. D. M. David, "Pseudo-Gruneisen Parameter of Molten Salts and their Binary Mixtures", $J$. Chem. Phys., 77, 1064, 1982.

[7] J. D. Pandey, A. K. Shukla, N. Tripathi, G. P. Dubey, "Internal pressure, ultrasonic velocity and viscosity of multi-component liquid systems", Pramana J. Phys., 40, 1-87, 1993.

[8] J. H. Hildebrand and R. L. Scott, The Solubility of NonElectrolytes, $3^{\text {rd }}$ ed., Dover Publication, New York, NY, 1964.

[9] M. R. J Dack, "Solvent structure. The use of internal pressure and cohesive energy density to examine contributions to solvent-solvent interactions", Aust. J. Chem., 28, 1643 - 1648, 1975.

[10] D. F. Grant-Taylor, D. D. Macdonald, "Water system + Thermal Pressure and Energy-Volume Coefficients for the acetonitrile", Can. J. Chem., 54, 2813-2819, 1976.

[11] D. D. Macdonald, J. B. Hyne, "The Thermal Pressure and Energy-Volume Coefficients of Dimethyl Sulfoxide Water Mixtures", Can. J. Chem., 49, 611-617, 1971.

[12] J. D. Pandey, N. Tripathi, R. Dey, "Thermodynamic and thermo-Acoustical Parameters of Pure Liquids at Elevated Pressures", Ind. J. Phys., 70B, 147 -155, 1996.

[13] B. K. Sharma, "Nonlinearity acoustical parameter and its relation with Rao's Acoustical Parameter of liquid state", Acoust. Soc. Am., 73, 106, 1983.

[14] J. D. Pandey, A. K. Singh, R. Dey, "Novel Approach for the Prediction of Ultrasonic Velocity in Quaternary Liquid Mixtures", Pramana J. Phys, 64, 135-139, 2005.

[15] Ranjan Dey, A. K. Singh, J. D. Pandey, "A New Theoretical Approach for Estimating Excess Internal Pressure", J. Molliq. Liq., 124,121-123, 2006.

[16] R. K. Shukla, A. Kumar, "Internal Pressure, Energy of Vaporization and Solubility Parameter of $\mathrm{Pb}-\mathrm{Sn}$ Molten Binary Mixture at Elevated Temperatures", Acta. Chim. Solv., 55, 627-631, 2008.

[17] R. K. Shukla, S. Shukla, V. Pandey, P. Awasthi, "Sound Velocity, Effective Debye Temperature and Pseudo-Gruneisen Parameter of Pb-Sn Molten Mixture at Elevated Temperatures", J.Phys. \& Chem. Liq., 45, 169-180, 2007.

[18] R. K. Shukla, V. K. Pundhir, V. S. Gangwar, Kirti Srivastava, "Thermo-acoustical and Allied Properties of Binary Liquid Systems", J. Pure Appl. Ultrason, 35, 35-43, 2013.

[19] P. Jain, M. Singh, "Density, Viscosity, and Excess Properties of Binary Liquid Mixtures of Propylene
Carbonate with Polar and Nonpolar Solvents", J. Chem. Eng. Data., 49, 1214-1217, 2004.

[20] J. D. Pandey, N. K. Soni, R. Day, R. Verma, "Excess Functions of Binary Liquid Mixtures at Varying Pressures", Fluid Phase Equil, 15, 17-22, 2004.

[21] R. K. Shukla, A. Kumar, N. Awasthi, U. Srivastava, K. Srivastava, "Speed of Sound and Isentropic Compressibility of Benzonitrile, Chlorobenzene, Benzyl chloride and Benzyl alcohol with Benzene from Various Models at Temperature Range 298.15 to 313.15 K", Arabian J. of Chem. DOI:10.1016/ j.arabjc.2014.07. 0132014)

[22] A. Abe, P. J. Flory, "The thermodynamic properties of mixtures of small non-polar molecules", J. Am. Chem. Soc., 82, 1838-1845,1965.

[23] P. J. Flory, R. A. Orwoll, A. Vrij, "Statistical thermodynamics of chain molecule liquids, liquid mixtures of normal paraffin hydrocarbon", J. Amer. Chem. Soc., 86, 3515-3520, 1964.

[24] K. Ramaswamy, D. Anbananthan, original article unavailable, information taken from Ref. [3], Acustica, $48,281-282,1981$

[25] J. Glinski, "Determination of the conditional association constants from the sound velocity data in binary liquid mixtures", J. Chem. Phy., 118, 23012307, 2003.

[26] O. Redlich, A.T. Kister, "Thermodynamics of nonelectrolytic solutions. Algebric representation of thermodynamic properties and the classification of solutions", Ind. Eng. Chem., 40, 345-348, 1948.

[27] G. Natta, M. Baccaredda, Atti Accad. Naz. Lincei., 4, $360,1948$.

[28] R. K. Shukla, N. Awasthi, A. Kumar, A. Shukla, V. K. Pandey, "Prediction of Associational Behaviour of Binary Liquid Mixtures from Viscosity Data", $J$. Molliq. Liq., 158, 131-138, 2011.

[29] J. D. Pandey, R. Verma, "Inversion of the KirkwoodBuff theory of solutions: Application to binary systems", Chem. Phys., 270, 429-438, 2001.

[30] A. Riddick, W. B. Bunger and T. K. Sakano, Organic Solvents Techniques of Chemistry, $4^{\text {th }}$ Ed. Willey: New York, 1986.

[31] S. J. Askar, A. Ali, "Effect of temperature on the molecular dynamics of some binary mixtures by ultrasonic method", J. Chem. \& Pharm. Res., 4, 617632,2012

[32]AL-Kandary, A. Jasem, AL-Jimaz, S. Adel, A. Haq, M. A. Latif, "Viscosities, Densities, and Speeds of Sound of Binary Mixtures of Benzene, Toluene, o-Xylene, mXylene, p-Xylene, and Mesitylene with Anisole at (288.15, 293.15, 298.15, and 303.15) K", J. Chem. Eng. Data.,51, 2074-2082, 2006.

[33] L-Jimaz., S. Adel, AL-Kandary, A. Jasem, A. Haq, M. A Latif, "Acoustical and Excess Properties of \{Chlorobenzene + 1-Hexanol, or 1-Heptanol, or 1Octanol, or 1-Nonanol, or 1-Decanol $\}$ at (298.15, 303.15, 308.15, and 313.15) K", J. Chem. Eng. Data. 52, 206-214, 2007. 
Table 4. Pseudo-Gruniesen Values, Excess Pseudo-Gruniesen Values and Internal Pressures from Various Models for Binary Liquid Mixtures at Various Temperatures.

\begin{tabular}{|c|c|c|c|c|c|c|c|c|c|c|c|c|}
\hline \multicolumn{13}{|l|}{298.15} \\
\hline 0.1681 & -2.881 & -2.8425 & -2.8543 & -2.8336 & -0.047 & -0.008 & -0.020 & 0.000 & 5.5970 & 5.1590 & 5.4410 & 5.3230 \\
\hline 0.3126 & -2.861 & -2.7622 & -2.8015 & -2.7716 & -0.087 & 0.010 & -0.028 & 0.001 & 5.4890 & 4.9060 & 5.1540 & 4.9900 \\
\hline 0.4381 & -2.827 & -2.6911 & -2.7541 & -2.7215 & -0.107 & 0.029 & -0.033 & -0.001 & 5.3090 & 4.6860 & 4.9050 & 4.7330 \\
\hline 0.5481 & -2.799 & -2.6277 & -2.7097 & -2.6784 & -0.125 & 0.046 & -0.035 & -0.004 & 5.1620 & 4.4920 & 4.6810 & 4.5210 \\
\hline 0.6453 & -2.772 & -2.5715 & -2.6736 & -2.6456 & -0.139 & 0.061 & -0.040 & -0.012 & 5.0200 & 4.3200 & 4.5020 & 4.3620 \\
\hline 0.7318 & -2.710 & -2.5201 & -2.6331 & -2.6099 & -0.114 & 0.076 & -0.036 & -0.013 & 4.7050 & 4.1680 & 4.3110 & 4.1980 \\
\hline 0.8093 & -2.675 & -2.4747 & -2.6035 & -2.5857 & -0.111 & 0.089 & -0.039 & -0.021 & 4.5300 & 4.0310 & 4.1720 & 4.0870 \\
\hline 0.8792 & -2.602 & -2.4317 & -2.5616 & -2.5498 & -0.067 & 0.103 & -0.026 & -0.014 & 4.1800 & 3.9080 & 3.9880 & 3.9330 \\
\hline 0.9423 & -2.557 & -2.3908 & -2.5129 & -2.5070 & -0.048 & 0.117 & -0.004 & 0.001 & 3.9870 & 3.8010 & 3.7840 & 3.7570 \\
\hline \multicolumn{13}{|l|}{303.15} \\
\hline 0.1681 & -2.822 & -2.7632 & -2.7790 & -2.7599 & -0.065 & -0.006 & -0.022 & -0.003 & 5.6160 & 5.2160 & 5.3620 & 5.2520 \\
\hline 0.3126 & -2.805 & -2.6890 & -2.7352 & -2.7076 & -0.103 & 0.012 & -0.033 & -0.006 & 5.5210 & 4.9710 & 5.1180 & 4.9650 \\
\hline 0.4381 & -2.779 & -2.6232 & -2.6945 & -2.6645 & -0.125 & 0.030 & -0.040 & -0.010 & 5.3780 & 4.7570 & 4.8990 & 4.7380 \\
\hline 0.5481 & -2.745 & -2.5645 & -2.6564 & -2.6276 & -0.133 & 0.047 & -0.044 & -0.015 & 5.1880 & 4.5700 & 4.7020 & 4.5500 \\
\hline 0.6453 & -2.732 & -2.5131 & -2.6288 & -2.6030 & -0.157 & 0.062 & -0.053 & -0.027 & 5.1170 & 4.4040 & 4.5580 & 4.4250 \\
\hline 0.7318 & -2.656 & -2.4643 & -2.5841 & -2.5628 & -0.114 & 0.077 & -0.041 & -0.020 & 4.7220 & 4.2560 & 4.3450 & 4.2380 \\
\hline 0.8093 & -2.606 & -2.4202 & -2.5421 & -2.5259 & -0.093 & 0.092 & -0.029 & -0.013 & 4.4750 & 4.1240 & 4.1510 & 4.0720 \\
\hline 0.8792 & -2.555 & -2.3815 & -2.5135 & -2.5027 & -0.069 & 0.104 & -0.027 & 0.016 & 4.2220 & 4.0040 & 4.0200 & 3.9680 \\
\hline 0.9423 & -2.500 & -2.3436 & -2.4659 & -2.4605 & -0.038 & 0.118 & -0.003 & 0.001 & 3.9800 & 3.8970 & 3.8150 & 3.7910 \\
\hline \multicolumn{13}{|l|}{308.15} \\
\hline 0.1681 & -2.755 & -2.7035 & -2.7253 & -2.7057 & -0.036 & 0.015 & -0.006 & 0.013 & 5.5720 & 5.3290 & 5.3900 & 5.2740 \\
\hline 0.3126 & -2.750 & -2.6291 & -2.6835 & -2.6552 & -0.089 & 0.032 & -0.021 & 0.006 & 5.5450 & 5.0720 & 5.1490 & 4.9880 \\
\hline 0.4381 & -2.715 & -2.5616 & -2.6332 & -2.6026 & -0.103 & 0.050 & -0.021 & 0.009 & 5.3500 & 4.8480 & 4.8790 & 4.7100 \\
\hline 0.5481 & -2.686 & -2.5036 & -2.6018 & -2.5722 & -0.118 & 0.064 & -0.033 & -0.004 & 5.1850 & 4.6510 & 4.7080 & 4.5490 \\
\hline 0.6453 & -2.680 & -2.4517 & -2.5730 & -2.5467 & -0.150 & 0.077 & -0.043 & -0.017 & 5.1500 & 4.4770 & 4.5560 & 4.4170 \\
\hline 0.7318 & -2.598 & -2.4030 & -2.5301 & -2.5083 & -0.103 & 0.092 & -0.034 & -0.013 & 4.7100 & 4.3230 & 4.3450 & 4.2340 \\
\hline 0.8093 & -2.548 & -2.3579 & -2.4827 & -2.4662 & -0.083 & 0.106 & -0.018 & -0.001 & 4.4600 & 4.1840 & 4.1240 & 4.0420 \\
\hline
\end{tabular}




\begin{tabular}{llllllllllllll}
0.8792 & -2.505 & -2.3198 & -2.4593 & -2.4482 & -0.068 & 0.116 & -0.022 & -0.011 & 4.2420 & 4.0600 & 4.0120 & 3.9580 \\
0.9423 & -2.455 & -2.3364 & -2.4138 & -2.4083 & -0.043 & 0.075 & -0.002 & 0.003 & 4.0120 & 3.5320 & 3.8120 & 3.7860 \\
313.15 & & & & & & & & & & & \\
0.1681 & -2.709 & -2.6376 & -2.6709 & -2.6495 & -0.045 & 0.025 & -0.007 & 0.013 & 5.6350 & 5.4100 & 5.4000 & 5.2710 \\
0.3126 & -2.690 & -2.5620 & -2.6201 & -2.5894 & -0.084 & 0.043 & -0.014 & 0.016 & 5.5310 & 5.1430 & 5.1070 & 4.9300 \\
0.4381 & -2.669 & -2.4962 & -2.5827 & -2.5495 & -0.113 & 0.059 & -0.026 & 0.006 & 5.4050 & 4.9100 & 4.8950 & 4.7080 \\
0.5481 & -2.618 & -2.4366 & -2.5394 & -2.5075 & -0.106 & 0.075 & -0.027 & 0.004 & 5.1140 & 4.7050 & 4.6630 & 4.4890 \\
0.6453 & -2.620 & -2.3852 & -2.5139 & -2.4855 & -0.146 & 0.088 & -0.040 & -0.012 & 5.1200 & 4.5250 & 4.5230 & 4.3710 \\
0.7318 & -2.529 & -2.3358 & -2.4665 & -2.4431 & -0.090 & 0.103 & -0.027 & -0.004 & 4.6240 & 4.3640 & 4.2890 & 4.1680 \\
0.8093 & -2.482 & -2.2924 & -2.4312 & -2.4133 & -0.074 & 0.115 & -0.022 & -0.005 & 4.3820 & 4.2210 & 4.1170 & 4.0270 \\
0.8792 & -2.437 & -2.2531 & -2.3979 & -2.3860 & -0.057 & 0.127 & -0.017 & -0.005 & 4.1590 & 4.0920 & 3.9600 & 3.9010 \\
0.9423 & -2.357 & -2.2163 & -2.3589 & -2.3530 & -0.001 & 0.139 & -0.003 & 0.002 & 3.7750 & 3.9760 & 3.7840 & 3.7550 \\
\hline
\end{tabular}

Benzene+chlorobenzene

\begin{tabular}{|c|c|c|c|c|c|c|c|c|c|c|c|c|}
\hline $\mathrm{X}_{1}$ & Гobs & $\Gamma$ PFP & $\Gamma_{\mathrm{RS}}$ & $\Gamma$ GLI & $\Gamma^{\mathrm{E}_{\text {Obs }}}$ & $\Gamma^{\mathrm{E}}$ PFP & $\Gamma^{\mathrm{E}_{\mathrm{RS}}}$ & $\Gamma^{\mathrm{E}_{\mathrm{GLI}}}$ & $\begin{array}{c}\text { Piobs10- } \\
\quad{ }^{\circ} / \mathrm{Pa} \\
\end{array}$ & $\begin{array}{c}\text { PiPFP } \\
10^{-9} \\
\end{array}$ & $\begin{array}{c}\text { Pi RS } \\
10^{-9} \\
\end{array}$ & $\begin{array}{c}\text { PigLI } \\
10^{-9} \\
\end{array}$ \\
\hline \multicolumn{13}{|l|}{298.15} \\
\hline 0.1808 & -2.812 & -2.8536 & -2.7846 & -2.7914 & 0.039 & -0.002 & 0.067 & 0.060 & 5.2070 & 5.4520 & 5.0540 & 5.0920 \\
\hline 0.3318 & -2.783 & -2.7664 & -2.7433 & -2.7539 & 0.001 & 0.017 & 0.040 & 0.030 & 5.0540 & 5.1570 & 4.8400 & 4.8970 \\
\hline 0.4598 & -2.749 & -2.6896 & -2.6951 & -2.7074 & -0.023 & 0.037 & 0.031 & 0.019 & 4.8910 & 4.9060 & 4.6040 & 4.6680 \\
\hline 0.5697 & -2.733 & -2.6251 & -2.6710 & -2.6835 & -0.055 & 0.052 & 0.006 & -0.006 & 4.8030 & 4.6890 & 4.4830 & 4.5460 \\
\hline 0.6651 & -2.716 & -2.5675 & -2.6405 & -2.6522 & -0.082 & 0.067 & -0.006 & -0.017 & 4.7230 & 4.5010 & 4.3380 & 4.3960 \\
\hline 0.7487 & -2.691 & -2.5158 & -2.6073 & -2.6175 & -0.094 & 0.081 & -0.010 & -0.020 & 4.6040 & 4.3350 & 4.1870 & 4.2360 \\
\hline 0.8225 & -2.674 & -2.4709 & -2.5845 & -2.5926 & -0.110 & 0.093 & -0.020 & -0.028 & 4.5250 & 4.1890 & 4.0830 & 4.1210 \\
\hline 0.8882 & -2.602 & -2.4289 & -2.5502 & -2.5558 & -0.067 & 0.105 & -0.015 & -0.021 & 4.1800 & 4.0590 & 3.9350 & 3.9610 \\
\hline 0.9470 & -2.554 & -2.3894 & -2.5052 & -2.5080 & -0.046 & 0.118 & 0.002 & 0.000 & 3.9780 & 3.9430 & 3.7510 & 3.7630 \\
\hline \multicolumn{13}{|l|}{303.15} \\
\hline 0.1808 & -2.742 & -2.7838 & -2.7219 & -2.7281 & 0.052 & 0.010 & 0.072 & 0.066 & 5.1520 & 5.2880 & 5.0370 & 5.0720 \\
\hline $\begin{array}{l}0.3318 \\
0.4598\end{array}$ & $\begin{array}{l}-2.722 \\
-2.690\end{array}$ & $\begin{array}{l}-2.7009 \\
-2.6282\end{array}$ & $\begin{array}{l}-2.6839 \\
-2.6414\end{array}$ & $\begin{array}{l}-2.6936 \\
-2.6526\end{array}$ & $\begin{array}{r}0.006 \\
-0.017\end{array}$ & $\begin{array}{l}0.028 \\
0.045\end{array}$ & $\begin{array}{l}0.045 \\
0.032\end{array}$ & $\begin{array}{l}0.035 \\
0.021\end{array}$ & $\begin{array}{l}5.0470 \\
4.8880\end{array}$ & $\begin{array}{l}5.0130 \\
4.7800\end{array}$ & $\begin{array}{l}4.8360 \\
4.6230\end{array}$ & $\begin{array}{l}4.8890 \\
4.6820\end{array}$ \\
\hline 0.5697 & -2.681 & -2.5671 & -2.6202 & -2.6317 & -0.055 & 0.059 & 0.006 & -0.005 & 4.8390 & 4.5790 & 4.5120 & 4.5720 \\
\hline 0.6651 & -2.670 & -2.5133 & -2.5993 & -2.6101 & -0.085 & 0.071 & -0.014 & -0.025 & 4.7770 & 4.4050 & 4.4070 & 4.4620 \\
\hline 0.7487 & -2.638 & -2.4633 & -2.5612 & -2.5705 & -0.089 & 0.085 & -0.012 & -0.021 & 4.6260 & 4.2530 & 4.2310 & 4.2770 \\
\hline
\end{tabular}

Int. J. of Thermodynamics (IJoT)

Vol. 18 (No. 3) / 156 


\begin{tabular}{|c|c|c|c|c|c|c|c|c|c|c|c|c|}
\hline 0.8225 & -2.605 & -2.4187 & -2.5253 & -2.5326 & -0.088 & 0.098 & -0.008 & -0.015 & 4.4700 & 4.1190 & 4.0700 & 4.1050 \\
\hline 0.8882 & -2.555 & -2.3803 & -2.5033 & -2.5084 & -0.066 & 0.108 & -0.014 & -0.019 & 4.2220 & 4.0010 & 3.9710 & 3.9950 \\
\hline $\begin{array}{l}0.9470 \\
308.15\end{array}$ & -2.499 & -2.3426 & -2.4600 & -2.4625 & -0.036 & 0.120 & 0.003 & 0.001 & 3.9760 & 3.8950 & 3.7890 & 3.8010 \\
\hline 0.1808 & -2.685 & -2.7134 & -2.6609 & -2.6666 & 0.052 & 0.024 & 0.076 & 0.071 & 5.1530 & 5.3630 & 5.0130 & 5.0460 \\
\hline 0.3318 & -2.664 & -2.6317 & -2.6237 & -2.6326 & 0.008 & 0.041 & 0.049 & 0.040 & 5.0430 & 5.0820 & 4.8130 & 4.8630 \\
\hline 0.4598 & -2.628 & -2.5589 & -2.5735 & -2.5837 & -0.010 & 0.059 & 0.045 & 0.035 & 4.8620 & 4.8430 & 4.5610 & 4.6160 \\
\hline 0.5697 & -2.628 & -2.5001 & -2.5611 & -2.5716 & -0.056 & 0.071 & 0.010 & 0.000 & 4.8530 & 4.6390 & 4.4910 & 4.5460 \\
\hline 0.6651 & -2.618 & -2.4471 & -2.5394 & -2.5492 & -0.087 & 0.084 & -0.008 & -0.01 & 4.8030 & 4.4620 & 4.3800 & 4.4310 \\
\hline 0.7487 & -2.593 & -2.3983 & -2.5040 & -2.5125 & -0.097 & 0.097 & -0.008 & -0.01 & 4.6800 & 4.3070 & 4.2130 & 4.2560 \\
\hline 0.8225 & -2.547 & -2.3539 & -2.4637 & -2.4704 & -0.082 & 0.110 & 0.000 & -0.006 & 4.4550 & 4.1710 & 4.0310 & 4.0640 \\
\hline 0.8882 & -2.505 & -2.3170 & -2.4477 & -2.4523 & -0.069 & 0.119 & -0.011 & -0.016 & 4.2420 & 4.0500 & 3.9560 & 3.9780 \\
\hline $\begin{array}{l}0.9470 \\
313.15\end{array}$ & -2.455 & -2.2805 & -2.4083 & -2.4106 & -0.043 & 0.130 & 0.003 & 0.001 & 4.0120 & 3.9430 & 3.7860 & 3.7970 \\
\hline 0.1808 & -2.602 & -2.6078 & -2.5762 & -2.5814 & 0.051 & 0.046 & 0.078 & 0.072 & 4.9990 & 5.2980 & 4.8460 & 4.8760 \\
\hline 0.3318 & -2.574 & -2.5327 & -2.5407 & -2.5489 & 0.020 & 0.062 & 0.054 & 0.046 & 4.8440 & 5.0350 & 4.6570 & 4.7020 \\
\hline 0.4598 & -2.541 & -2.4677 & -2.5061 & -2.5155 & 0.003 & 0.077 & 0.038 & 0.029 & 4.6710 & 4.8110 & 4.4790 & 4.5300 \\
\hline 0.5697 & -2.519 & -2.4123 & -2.4841 & -2.4937 & -0.017 & 0.089 & 0.017 & 0.007 & 4.5540 & 4.6180 & 4.3650 & 4.4160 \\
\hline 0.6651 & -2.510 & -2.3646 & -2.4695 & -2.4785 & -0.046 & 0.099 & -0.005 & -0.014 & 4.5080 & 4.4510 & 4.2880 & 4.3350 \\
\hline 0.7487 & -2.465 & -2.3192 & -2.4324 & -2.4402 & -0.034 & 0.112 & -0.001 & -0.009 & 4.2830 & 4.3050 & 4.1140 & 4.1530 \\
\hline 0.8225 & -2.432 & -2.2799 & -2.4062 & -2.4123 & -0.030 & 0.122 & -0.004 & -0.010 & 4.1250 & 4.1770 & 3.9920 & 4.0230 \\
\hline 0.8882 & -2.378 & -2.2449 & -2.3825 & -2.3867 & -0.001 & 0.131 & -0.006 & -0.010 & 3.8620 & 4.0630 & 3.8840 & 3.9050 \\
\hline 0.9470 & -2.351 & -2.2121 & -2.3506 & -2.3527 & 0.001 & 0.141 & 0.002 & 0.001 & 3.7480 & 3.9610 & 3.7450 & 3.7550 \\
\hline \multicolumn{13}{|c|}{ Benzene+benzalchloride } \\
\hline $\mathrm{x}_{1}$ & Гobs & $\Gamma$ PFP & $\Gamma_{\mathrm{RS}}$ & $\Gamma$ GLI & $\Gamma^{\mathrm{E}_{\text {Obs }}}$ & $\Gamma^{\mathrm{E}}$ PFP & $\Gamma_{\mathrm{RS}}^{\mathrm{E}_{\mathrm{R}}}$ & $\Gamma_{\mathrm{GLI}}$ & $\begin{array}{c}\text { Piobs } 10^{-} \\
{ }_{9}^{9} / \mathrm{Pa} \\
\end{array}$ & $\begin{array}{c}\text { PiPFP } \\
10^{-9} \\
\end{array}$ & $\begin{array}{c}\mathrm{Pi}_{\mathrm{RS}} \\
10^{-9} \\
\end{array}$ & $\begin{array}{c}\text { Pi }_{\text {GLI }} \\
10^{-9} \\
\end{array}$ \\
\hline \multicolumn{13}{|l|}{298.15} \\
\hline 0.1988 & -2.682 & -2.6829 & -2.6777 & -2.6818 & 0.046 & 0.046 & 0.051 & 0.047 & 4.5150 & 4.6410 & 4.4920 & 4.5120 \\
\hline 0.3583 & -2.677 & -2.6243 & -2.6634 & -2.6696 & 0.002 & 0.055 & 0.016 & 0.010 & 4.4920 & 4.4640 & 4.4210 & 4.4520 \\
\hline 0.4894 & -2.646 & -2.5726 & -2.6341 & -2.6412 & -0.006 & 0.067 & 0.006 & -0.001 & 4.3510 & 4.3150 & 4.2890 & 4.3240 \\
\hline 0.5982 & -2.633 & -2.5300 & -2.6206 & -2.6276 & -0.026 & 0.076 & -0.013 & -0.020 & 4.2870 & 4.1870 & 4.2270 & 4.2610 \\
\hline 0.6907 & -2.595 & -2.4910 & -2.5917 & -2.5981 & -0.016 & 0.087 & -0.013 & -0.019 & 4.1190 & 4.0770 & 4.1030 & 4.1330 \\
\hline 0.7701 & -2.561 & -2.4568 & -2.5643 & -2.5698 & -0.007 & 0.097 & -0.009 & -0.015 & 3.9750 & 3.9810 & 3.9880 & 4.0130 \\
\hline
\end{tabular}




\begin{tabular}{|c|c|c|c|c|c|c|c|c|c|c|c|c|}
\hline 0.8392 & -2.535 & -2.4273 & -2.5433 & -2.5476 & -0.002 & 0.106 & -0.009 & -0.014 & 3.8660 & 3.8970 & 3.9000 & 3.9200 \\
\hline 0.8993 & -2.494 & -2.3994 & -2.5112 & -2.5141 & 0.020 & 0.115 & 0.003 & 0.002 & 3.6960 & 3.8230 & 3.7720 & 3.7850 \\
\hline $\begin{array}{l}0.9526 \\
303.15\end{array}$ & -2.476 & -2.3765 & -2.4953 & -2.4968 & 0.022 & 0.122 & 0.003 & 0.002 & 3.6250 & 3.7560 & 3.7080 & 3.7150 \\
\hline 0.1988 & 2.6407 & -2.6175 & -2.6280 & -2.6311 & 0.031 & 0.054 & 0.044 & 0.041 & 4.5890 & 4.7170 & 4.5230 & 4.5390 \\
\hline 0.3583 & -2.615 & -2.5609 & -2.6015 & -2.6062 & 0.010 & 0.065 & 0.024 & 0.019 & 4.4720 & 4.5450 & 4.3990 & 4.4220 \\
\hline 0.4894 & -2.597 & -2.5134 & -2.5808 & -2.5861 & -0.009 & 0.074 & 0.007 & 0.002 & 4.3860 & 4.4000 & 4.3030 & 4.3300 \\
\hline 0.5982 & -2.580 & -2.4740 & -2.5723 & -2.5776 & -0.024 & 0.082 & -0.015 & -0.021 & 4.3030 & 4.2760 & 4.2620 & 4.2880 \\
\hline 0.6907 & -2.542 & -2.4372 & -2.5427 & -2.5475 & -0.012 & 0.092 & -0.013 & -0.017 & 4.1300 & 4.1690 & 4.1320 & 4.1560 \\
\hline 0.7701 & -2.514 & -2.4051 & -2.5158 & -2.5198 & -0.008 & 0.101 & -0.009 & -0.013 & 4.0120 & 4.0760 & 4.0170 & 4.0360 \\
\hline 0.8392 & -2.482 & -2.3767 & -2.4904 & -2.4935 & 0.004 & 0.110 & -0.003 & -0.006 & 3.8710 & 3.9940 & 3.9100 & 3.9250 \\
\hline 0.8993 & -2.452 & -2.3518 & -2.4686 & -2.4708 & 0.017 & 0.117 & 0.000 & -0.001 & 3.7450 & 3.9220 & 3.8200 & 3.8300 \\
\hline 0.9526 & -2.426 & -2.3299 & -2.4502 & -2.4513 & 0.027 & 0.124 & 0.003 & 0.003 & 3.6390 & 3.8570 & 3.7450 & 3.7500 \\
\hline 308.15 & & & & & & & & & & & & \\
\hline 0.1988 & 2.4935 & -2.5468 & -2.4821 & -2.4852 & 0.131 & 0.077 & 0.142 & 0.139 & 4.1800 & 4.8140 & 4.1220 & 4.1380 \\
\hline 0.3583 & -2.568 & -2.5031 & -2.5549 & -2.5599 & 0.009 & 0.074 & 0.022 & 0.017 & 4.5060 & 4.6320 & 4.4360 & 4.4620 \\
\hline 0.4894 & -2.549 & -2.4536 & -2.5249 & -2.5305 & -0.010 & 0.085 & 0.014 & 0.008 & 4.4200 & 4.4790 & 4.2960 & 4.3240 \\
\hline 0.5982 & -2.510 & -2.4112 & -2.4974 & -2.5029 & -0.003 & 0.095 & 0.009 & 0.004 & 4.2360 & 4.3480 & 4.1700 & 4.1980 \\
\hline 0.6907 & -2.487 & -2.3758 & -2.4817 & -2.4868 & -0.008 & 0.103 & -0.002 & -0.007 & 4.1290 & 4.2350 & 4.0990 & 4.1240 \\
\hline 0.7701 & -2.468 & -2.3449 & -2.4666 & -2.4709 & -0.012 & 0.111 & -0.010 & -0.014 & 4.0410 & 4.1370 & 4.0310 & 4.0520 \\
\hline 0.8392 & -2.421 & -2.3159 & -2.4386 & -2.4420 & 0.014 & 0.120 & -0.002 & -0.005 & 3.8290 & 4.0510 & 3.9110 & 3.9270 \\
\hline 0.8993 & -2.389 & -2.2907 & -2.4162 & -2.4185 & 0.029 & 0.127 & 0.002 & -0.000 & 3.6900 & 3.9750 & 3.8160 & 3.8270 \\
\hline $\begin{array}{l}0.9526 \\
313.15\end{array}$ & -2.389 & -2.2604 & -2.4227 & -2.4239 & 0.013 & 0.142 & -0.020 & -0.021 & 3.6850 & 3.9940 & 3.8410 & 3.8460 \\
\hline 0.1988 & -2.432 & -2.4867 & -2.4245 & -2.4282 & -0.070 & -0.124 & -0.062 & -0.065 & 4.1350 & 4.8990 & 4.0920 & 4.1110 \\
\hline 0.3583 & -2.512 & -2.9067 & -2.4960 & -2.5019 & -0.155 & -0.550 & -0.139 & -0.145 & 4.4900 & 6.5220 & 4.4040 & 4.4350 \\
\hline 0.4894 & -2.497 & -2.7649 & -2.4662 & -2.4728 & -0.145 & -0.413 & -0.114 & -0.121 & 4.4250 & 5.9770 & 4.2610 & 4.2960 \\
\hline 0.5982 & -2.464 & -2.6438 & -2.4446 & -2.4512 & -0.117 & -0.296 & -0.097 & -0.103 & 4.2630 & 5.5200 & 4.1600 & 4.1930 \\
\hline 0.6907 & -2.437 & -2.5385 & -2.4187 & -2.4247 & -0.093 & -0.194 & -0.074 & -0.080 & 4.1380 & 5.1340 & 4.0420 & 4.0720 \\
\hline 0.7701 & -2.406 & -2.4478 & -2.4011 & -2.4062 & -0.065 & -0.106 & -0.060 & -0.065 & 3.9890 & 4.8040 & 3.9620 & 3.9880 \\
\hline 0.8392 & -2.379 & -2.3680 & -2.3798 & -2.3837 & -0.041 & -0.029 & -0.041 & -0.045 & 3.8670 & 4.5190 & 3.8680 & 3.8880 \\
\hline 0.8993 & -2.345 & -2.2984 & -2.3613 & -2.3640 & -0.009 & 0.037 & -0.025 & -0.027 & 3.7120 & 4.2730 & 3.7880 & 3.8010 \\
\hline 0.9526 & -2.324 & -2.2374 & -2.3452 & -2.3465 & 0.009 & 0.096 & -0.010 & -0.012 & 3.6210 & 4.0580 & 3.7190 & 3.7260 \\
\hline
\end{tabular}




\begin{tabular}{|c|c|c|c|c|c|c|c|c|c|c|c|c|}
\hline $\mathrm{x}_{1}$ & $\Gamma_{\text {Obs }}$ & $\Gamma$ PFP & $\Gamma_{\mathrm{rs}}$ & $\Gamma_{\mathrm{Gli}}$ & $\Gamma^{\mathrm{E}_{\text {Obs }}}$ & $\Gamma^{\mathrm{E}}{ }_{\mathrm{PFP}}$ & $\Gamma^{\mathrm{E}_{\mathrm{RS}}}$ & $\Gamma^{\mathrm{E}_{\mathrm{GLI}}}$ & Piobs & $\begin{array}{c}\text { PiPFP } \\
10^{-9} \\
\end{array}$ & $\begin{array}{c}\text { Pi RS } \\
10^{-9} \\
\end{array}$ & $\begin{array}{c}\text { PiGLI } \\
10^{-9} \\
\end{array}$ \\
\hline \multicolumn{13}{|l|}{298.15} \\
\hline $\begin{array}{l}0.1749 \\
0.3229 \\
0.4498 \\
0.5598 \\
0.6561 \\
0.7410\end{array}$ & $\begin{array}{l}-2.822 \\
-2.791 \\
-2.768 \\
-2.721 \\
-2.686 \\
-2.635\end{array}$ & $\begin{array}{l}-2.7947 \\
-2.7208 \\
-2.6556 \\
-2.5966 \\
-2.5450 \\
-2.4982\end{array}$ & $\begin{array}{l}-2.7911 \\
-2.7524 \\
-2.7140 \\
-2.6669 \\
-2.6300 \\
-2.5896\end{array}$ & $\begin{array}{l}-2.8022 \\
-2.7702 \\
-2.7353 \\
-2.6890 \\
-2.6511 \\
-2.6082\end{array}$ & $\begin{array}{l}-0.018 \\
-0.045 \\
-0.071 \\
-0.066 \\
-0.068 \\
-0.050\end{array}$ & $\begin{array}{l}0.008 \\
0.025 \\
0.041 \\
0.057 \\
0.072 \\
0.086\end{array}$ & $\begin{array}{r}0.012 \\
-0.006 \\
-0.017 \\
-0.012 \\
-0.012 \\
-0.005\end{array}$ & $\begin{array}{r}0.001 \\
-0.024 \\
-0.038 \\
-0.034 \\
-0.033 \\
-0.023\end{array}$ & $\begin{array}{l}5.2570 \\
5.0920 \\
4.9750 \\
4.7440 \\
4.5750 \\
4.3360\end{array}$ & $\begin{array}{l}5.0000 \\
4.7690 \\
4.5690 \\
4.3950 \\
4.2430 \\
4.1080\end{array}$ & $\begin{array}{l}5.0860 \\
4.8830 \\
4.6900 \\
4.4660 \\
4.2940 \\
4.1140\end{array}$ & $\begin{array}{l}5.1470 \\
4.9780 \\
4.8010 \\
4.5780 \\
4.3990 \\
4.2040\end{array}$ \\
\hline $\begin{array}{l}0.8166 \\
0.8841\end{array}$ & $\begin{array}{l}-2.585 \\
-2.554\end{array}$ & $\begin{array}{l}-2.4555 \\
-2.4194\end{array}$ & $\begin{array}{l}-2.5482 \\
-2.5269\end{array}$ & $\begin{array}{l}-2.5632 \\
-2.5375\end{array}$ & $\begin{array}{l}-0.029 \\
-0.025\end{array}$ & $\begin{array}{l}0.099 \\
0.109\end{array}$ & $\begin{array}{l}0.007 \\
0.002\end{array}$ & $\begin{array}{l}-0.008 \\
-0.008\end{array}$ & $\begin{array}{l}4.1100 \\
3.9680\end{array}$ & $\begin{array}{l}3.9880 \\
3.8810\end{array}$ & $\begin{array}{l}3.9370 \\
3.8430\end{array}$ & $\begin{array}{l}4.0060 \\
3.8920\end{array}$ \\
\hline $\begin{array}{l}0.9450 \\
303.15\end{array}$ & -2.516 & -2.3857 & -2.4995 & -2.5050 & -0.010 & 0.119 & 0.006 & 0.001 & 3.8040 & 3.7840 & 3.7290 & 3.7540 \\
\hline 0.1749 & -2.763 & -2.7289 & -2.7401 & -2.7504 & -0.014 & 0.020 & 0.008 & -0.001 & 5.2590 & 5.0890 & 5.1260 & 5.1840 \\
\hline 0.3229 & -2.735 & -2.6579 & -2.6986 & -2.7152 & -0.011 & 0.066 & 0.025 & 0.009 & 5.1100 & 4.8600 & 4.9070 & 4.9970 \\
\hline 0.4498 & -2.710 & -2.5959 & -2.6616 & -2.6814 & -0.039 & 0.075 & 0.009 & -0.010 & 4.9790 & 4.6630 & 4.7160 & 4.8220 \\
\hline 0.5598 & -2.663 & -2.5403 & -2.6204 & -2.6410 & -0.038 & 0.084 & 0.004 & -0.016 & 4.7380 & 4.4910 & 4.5150 & 4.6220 \\
\hline 0.6561 & -2.616 & -2.4905 & -2.5796 & -2.5992 & -0.031 & 0.093 & 0.004 & -0.014 & 4.5090 & 4.3400 & 4.3220 & 4.4220 \\
\hline 0.7410 & -2.558 & -2.4438 & -2.5255 & -2.5427 & -0.009 & 0.105 & 0.023 & 0.006 & 4.2440 & 4.2060 & 4.0810 & 4.1650 \\
\hline 0.8166 & -2.525 & -2.4051 & -2.4998 & -2.5137 & -0.008 & 0.112 & 0.017 & 0.003 & 4.0910 & 4.0870 & 3.9650 & 4.0320 \\
\hline 0.8841 & -2.501 & -2.3711 & -2.4813 & -2.4912 & -0.012 & 0.117 & 0.007 & -0.002 & 3.9750 & 3.9810 & 3.8820 & 3.9280 \\
\hline $\begin{array}{l}0.9450 \\
308.15\end{array}$ & -2.472 & -2.3402 & -2.4637 & -2.4688 & -0.008 & 0.123 & 0.000 & -0.004 & 3.8440 & 3.8860 & 3.8030 & 3.8270 \\
\hline 0.1749 & -2.698 & -2.7045 & -2.6736 & -2.6837 & -0.016 & -0.021 & 0.009 & -0.001 & 5.2220 & 5.3390 & 5.0770 & 5.1340 \\
\hline 0.3229 & -2.674 & -2.5804 & -2.6341 & -2.6503 & -0.044 & 0.049 & -0.004 & -0.020 & 5.0920 & 4.8960 & 4.8640 & 4.9540 \\
\hline 0.4498 & -2.651 & -2.5211 & -2.5979 & -2.6172 & -0.066 & 0.063 & -0.013 & -0.032 & 4.9710 & 4.7010 & 4.6760 & 4.7810 \\
\hline 0.5598 & -2.594 & -2.4677 & -2.5562 & -2.5763 & -0.049 & 0.077 & -0.010 & -0.030 & 4.6730 & 4.5310 & 4.4690 & 4.5760 \\
\hline 0.6561 & -2.553 & -2.4206 & -2.5206 & -2.5397 & -0.042 & 0.090 & -0.009 & -0.028 & 4.4680 & 4.3810 & 4.2970 & 4.3960 \\
\hline 0.7410 & -2.511 & -2.3772 & -2.4773 & -2.4942 & -0.030 & 0.103 & 0.003 & -0.013 & 4.2700 & 4.2490 & 4.0990 & 4.1830 \\
\hline 0.8166 & -2.467 & -2.3381 & -2.4372 & -2.4507 & -0.013 & 0.115 & 0.016 & 0.003 & 4.0680 & 4.1310 & 3.9200 & 3.9860 \\
\hline 0.8841 & -2.436 & -2.3049 & -2.4142 & -2.4238 & -0.006 & 0.125 & 0.015 & 0.006 & 3.9250 & 4.0260 & 3.8180 & 3.8630 \\
\hline $\begin{array}{l}0.9450 \\
313.15\end{array}$ & -2.378 & -2.2751 & -2.3946 & -2.3997 & 0.030 & 0.133 & 0.013 & 0.008 & 3.6540 & 3.9320 & 3.7310 & 3.7550 \\
\hline 0.1749 & -2.607 & -2.5308 & -2.5887 & -2.5974 & -0.018 & 0.058 & 0.001 & -0.008 & 5.0180 & 5.0090 & 4.9080 & 4.9580 \\
\hline 0.3229 & -2.623 & -2.4727 & -2.5585 & -2.5725 & -0.079 & 0.070 & -0.015 & -0.029 & 5.1110 & 4.8090 & 4.7430 & 4.8220 \\
\hline 0.4498 & -2.547 & -2.4205 & -2.5205 & -2.5372 & -0.044 & 0.083 & -0.016 & -0.033 & 4.6970 & 4.6360 & 4.5480 & 4.6390 \\
\hline 0.5598 & -2.605 & -2.3744 & -2.4865 & -2.5040 & -0.136 & 0.095 & -0.017 & -0.034 & 5.0370 & 4.4840 & 4.3780 & 4.4700 \\
\hline 0.6561 & -2.569 & -2.3321 & -2.4450 & -2.4615 & -0.129 & 0.107 & -0.005 & -0.021 & 4.8490 & 4.3510 & 4.1800 & 4.2650 \\
\hline 0.7410 & -2.487 & -2.2926 & -2.3948 & -2.4094 & -0.074 & 0.120 & 0.018 & 0.0037 & 4.4310 & 4.2330 & 3.9530 & 4.0250 \\
\hline 0.8166 & -2.435 & -2.2589 & -2.3625 & -2.3742 & -0.046 & 0.130 & 0.027 & 0.0154 & 4.1740 & 4.1270 & 3.8080 & 3.8650 \\
\hline 0.8841 & -2.401 & -2.2283 & -2.3304 & -2.3387 & -0.032 & 0.140 & 0.038 & 0.0299 & 4.0130 & 4.0330 & 3.6690 & 3.7080 \\
\hline 0.9450 & -2.369 & -2.2015 & -2.3068 & -2.3111 & -0.019 & 0.148 & 0.042 & 0.0385 & 3.8650 & 3.9470 & 3.5680 & 3.5880 \\
\hline
\end{tabular}

